\title{
Reinventing the biotech
}

\section{manager}

Biotechnology is a high-risk, fast-moving arena that requires quite a different breed of manager for success, say Jianming Li and William E Halal.

he biotechnology industry is one of the fastest growing sectors of the western economy, and the pace at which change takes place in this arena places unique demands on managers. Consequently, biotech managersmust be able to create and sustain an entrepreneurial and collaborative research-based organization within a high-risk environment. These

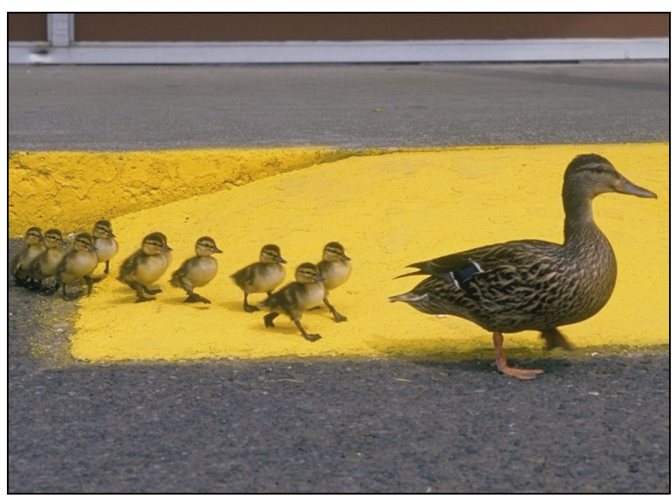
managerscannot simply imitate the management styles of other corporatepractices, but must develop their own manage ment philosophy compatiblewith the special nature of the biotechnology industry. This article looks at the distinctive characteristics of the biotechnology industry, and suggests an organizational structure and management philosophy desirablein biotechnology companies.

\section{A profile of the industry}

To develop a current profile of theindustry, we collected data on 414 public biotechnology companies listed on US stock markets. Analysis of these data produced the following snapshot of theindustry:

- Biotechnology companies are unevenly distributed in size, but in general are small. Although 32 companies employ more than 500 people, 163 companies employ fewer than 50 .

- Few biotechnology companies are prof-

Jianming $\mathrm{L} i$ is a biologist at the $\mathrm{N}$ ational Cancer Institute, Washington, DC, and William E. Halal is professor of management, The George Washington University, Washington, DC (halal@gwu.edu). companiesare drawn to major universities in California and the northeastern states to benefit from the proximity of scientific institutes, qualified personnel, and the intellectually stimulating environment that results.

- Biotechnology companies form alliances with pharmaceutical companies.

Biotechnology companies need pharmaceutical companies to gain access to capital, while pharmaceutical companies benefit from the entrepreneurial opportunities associated with biotechnology.

- Long product-development cycles make biotechnology a capital-intensive business. Biotechnology companies require large infusions of capital not only to start a venture but also to validate their technology and products.

So, what type of management would be best suited to an industry dependent on talented scientists who must work for many years at great risk to make scientific breakthroughs and then bring the fruits of this research to market?To answer this question, we have drawn on key aspects of progressive, well-performing companies such as Biogen, Human GenomeSciences, and Immunex, all of which practice at least some of the principles described here. In general, a high-tech, knowledge-based economy requiresthefollowing conditions (seeTable 1):

- an entrepreneurial research atmosphere;

- a collaborative corporate environment;

- a dominant focus on scientific values.

\section{A new management model}

Biotechnology is a costly and risky business in which few companies can achieve the major product breakthroughs needed for success. Indeed, thetop 3\% of all biotechnology companies produce $79 \%$ of the entireindustry's profit-most companies operate at a loss. Because the odds are against new biotechnology ventures ever becoming profitable, companies must build an organization that nur- 
tures a large number of diverse, highly entre preneurial efforts under one "roof "to improvetheir chances of success. A similar strategy is used in the publishing industry to manage the risk of book publishing: book publishers sell hundreds of books in several genres in the hopes of hitting on just a few profitable bestsellers. In both cases, pooling a large number of small, risky ventures reduces theoverall risk to the entire corporation.

There may also be somelessons to be learned by looking at how large pharmaceutical companies havestudied innovation in the biotechnology sector and reorganized their management teams to mimic it. The bureaucracy inherent in hierarchical corporations discourages creative research. As a consequence, progressive pharmaceutical companies have been re engineering themselves so that they can operate more likebiotech companies. For instance, M erck (Whitehouse Station, NJ) has been rated a top Fortune 500 company because its researchers pool their efforts and resources to carry out a diverse range of promising projects. M erck's former CEO, Roy Vagelos, described the system: "Everybody here gravitates around a hot project. The corporation is likea living organism." In a similar manner, GlaxoSmithKline (London) hassaid it will partition its organization into a series of autonomous research centers ("biotech hubs"), each focused on a specific therapeutic area, in the hopes of recreating a morestimulating and entrepreneurial environment.

In our eyes, the ideal biotechnology company thereforeshould beconstructed from several small, independent teams, or research ventures, that form spontaneously around promising concepts. This allows the company to pursue a variety of research avenues so that thetotal risk is reduced and the chance of at least a few ventures succeeding is increased.

Teams should beallowed almost complete freedom to choose their goals, supporting technology, personnel, working hours, resources, and almost all other aspects of their projects- exactly the same conditions in which entrepreneurs thrive. However, because no business can indulge researchers in unproductive, drawn-out projects, teams must be

Table 1. Contrasting management systems Industrial age Information age

\begin{tabular}{lll} 
Structure & Hierarchy & Internal enterprise \\
Culture & Conflict & Stakeholder collaboration \\
Mission & Profit & Profit, but also science and society \\
\hline
\end{tabular}

${ }^{*}$ Celera Genomics, for example, made a significant contribution to science and society by its contributions to the sequencing of the human genome, which were motivated by more than profit alone. held accountable for either completing specific pieces of research or developing products that are profitable.

This important link between freedom and accountability can be established by tying salaries and bonuses to the success of each team, or by offering stock options and other profit-sharing incentives. In addition to financial accountability, accolades from professional colleagues and company managers can encouragescientific personnel.

This "bottom-up" entrepreneurial system exhibits many of the characteristics associated with organic life. Organic systems provide large numbers of small, redundant units to ensurethe survival of the larger whole. Organic business models allow employees freedom to innovate, while competitive forces select themost successful ideas for the propagation of thebusiness.

Organic research organizations are al so favorable environments for professional and highly educated employees, who generally prefer to work in small, self-managed teams. Such structures al so suit biotechnology managers and scientists, many of whom are entrepreneurs or company founders.

Biotechnology managers need to pass on this entrepreneurial spirit to their employees, allowing them freedom to work as they think best whileholding them accountable for the results. (Further pointers on how to create entrepreneurial systems can be found in the reading list at the end of the article.)

\section{A culture of collaboration}

This decentralized, dispersed system, however, must be carefully integrated into a collaborative whole if it is to beeffective. Without a strong network of productive working relations, therewould belittlejustification for keeping these individual ventures together in a single organization. Thetotal value of the entireorganization must exceed the sum of its individual business units to offset the added cost of managing a larger system and to drive competitive advantage.

A strong ethos of collaboration is also needed to integrate the company with the various groups on which it depends for economic, intellectual, and political resources. Good working relations are needed with pharmaceutical companies, which providefunding and research support, and, later in the company's development, with theUS Food and Drug Administration

(Rockville, MD) and other regulatory agencies, which facilitate product approval. Close ties with academic institutions must al so be cultivated to ensure, for example, access to competent staff and cutting-edge research. Investors should also beinvolved in strategic decision making so that they feel confident their investment is being well managed.

$H$ iring and retaining skilled and committed professionals is crucial for all biotechnology companies, and managers need to assure staff that working conditions and remuneration are equitable. An entrepreneurial organization cannot pay everyone the same, but "equitable" treatment ensures that people will find the rules linking performance and reward to beacceptable.

This type of enterprise is seen as a constellation of collaborative partnerships with stakeholder groups-a"corporate community." Partners should share responsibility for the success of the enterprise and, in return, enjoy the right to influence decisions, realize benefits, and have their interests recognized as legitimate goals. Through this diverse blend of working relationships, theinterests of all stakeholders are enhanced.

\section{The focus is science}

Biotechnology is very different from other types of business because of itsfocus on scientific discovery and product development. In management terms, its "core competence" is science, rather than, for example, building information systems (IBM), drilling for oil (Exxon), or making pizza (Domino's).

In business, the culture of an organization drives its actions. We believe that to maintain an innovative culture, biotech management should avoid the temptation to devote undueattention to the pursuit of financial results, personal wealth, efficient operations, and other goals common to most corporations today. All those aims are necessary, but successful biotechnology companies should al ways emphasize the value of their science and technology, the importance of their research personnel, and their ultimate goal of contributing to medicine and human well-being.

The focus on scientific innovation must be most clearly observed in the treatment of a company's research staff. In general, biotechnology company employees are well-educated professionals who are knowledgeable about developments in their field, the scientific areas ripe for discovery, and the gaps in the market that need filling.

Public declaration about the value of employees isa well-worn cliché, but in the case of biotechnology it is true: theability to attract and engage sophisticated research personnel ispivotal to thesuccess of any biotech- 
nology enterprise. Brilliant leadership, generous amounts of capital, and all of the other accoutrements of businessultimately count for little unless a company can harness the creative talents of its staff. Biotechnology managers must therefore constantly strive to create an intellectually exciting environment that attracts innovative researchers, offering them wide-ranging freedom and rewards to encourage the development of products that will meet the challenges of a competitive market.

\section{The new biotech manager}

This profile of the ideal biotechnology business model helps to define thenewly emerging roles of managers. M odern managersmay not make all the major decisions nor hold all control within their organization, as managers did in the past, but their roleisno less vital. Indeed, the modern manager must play several roles in the new model of a biotechnology corporation-leader, facilitator, and statesperson.

As a leader, a biotechnology manager must provide the vision needed to energize the business and drive it to success. As a facilitator, the manager coordinates the activities of various teams, cultivating an environment that encourages excellence. Finally, as a statesperson, a manager must skillfully organize the give and take of alliances that engage stakeholders for the benefit of the entire corporate community. Biotechnology straddles the worlds of science and commerce, and so biotechnology executives must reconcile the demands of these two masters by assuring the primacy of research within the context of profitability.

$M$ any companies suffer from a serious lack of understanding on thesepoints. M any biotechnology companies fail not because of bad science, but because their management personnel did not havethe knowledge or skill to design and guidea complex research organization effectively. Scientists and medical doctors skilled in their scientific fields often know little about business and its management, let alone the more progressive manage ment concepts outlined above. Although many of these leaders are sufficiently intuitive to become outstanding managers, formal knowledge and training can make this path less daunting for the heroic few, and more successful for the average.
Theleaders of biotechnology who understand the new logic emerging from the trenches of dynamic business will find ample opportunities to demonstrate their talents. Armed with a newly emerging philosophy that recognizes the creativity of self-organizing systems united into a collaborative scientific community, this new breed of biotechnology manager will lead the industry into an era of unprecedented growth.

\section{Further reading}

Bains, W. Biotechnology from A to Z, Edn. 2 (Oxford Univ. Press, New York; 2001).

Halal, W.E. Internal Markets: Bringing the Power of Free Enterprise Inside Your Organization (Wiley, New York; 1993).

Halal, W.E. The New Management: $A$ Guide to the Parallel Revolutions in Technology, Business, and Leadership (Berrett-Koehler, San Francisco; 1998).

Halal, W.E. The Infinite Resource: Creating and Leading the Knowledge Enterprise (Jossey-Bass, San Francisco; 1998)

McKelvey, M. Evolutionary Innovations: The Business of Biotechnology (Oxford Univ. Press, New York; 2000).

Oliver, R. W. The Coming Biotech Age: The Business of Bio-Materials (McGraw-Hill, New York; 1999).

Sapienza, A, Managing Scientists: Leadership Strategies in Research and Development (John Wiley \& Sons, New York; 1995).

Sapienza, A, Stork, D. \& Lombardino, J. Leading Biotechnology Alliances: Right From the Start (Wiley-Liss, New York; 2001). 